\title{
Sphenoid Wall Dehiscence: A Preventable Cause of Iatrogenic Internal Carotid Artery Rupture
}

\author{
Prashant Punia*1, Ashish Chugh ${ }^{1}$, Sarang Gotecha ${ }^{1}$ and Vinod Shinde ${ }^{2}$ \\ ${ }^{1}$ Department of Neurosurgery, Dr DY Patil Medical College and Hospital, India \\ ${ }^{2}$ Department of Otorhinolaryngology, Dr D Y Patil medical College, India
}

Submission: September 22, 2020; Published: October 09, 2020

*Corresponding author: Prashant Punia, Department of Neurosurgery, Dr. DY Patil Medical College, Hospital and Research Center, Sant Tukaram Nagar, Pimpri, Pune

Keywords: Pituitary surgery complications, sphenoid wall dehiscence, internal carotid artery rupture, TNTS complications

- All sources of financial and material support including the following: NA

- Any portion of the contents of the paper may have not been presented or published previously.

\section{Introduction}

Minimally Invasive approaches to pituitary tumor have become gold standard not just for pituitary surgery but also for pathologies of ventral skull base [1]. It is due to the fantastic view it offers and the ease of doing surgery. The same, however, are not without complications and rupture of Internal Carotid Artery (ICA) is potentially the most catastrophic and thus, most feared [2]. ICA is unique in presenting the number of curvatures intracranial, especially through its passage out of carotid canal and along the side of sphenoid bone where its form resembles the English alphabet S[3].The incidence of ICA rupture in trans sphenoidal surgeries is $1.1 \%$ [4] and is limited to a few case reports. There is hardly any standard protocol available for the management of the same and considering the ever increasing applicability and use of Trans sphenoidal surgery, this incidence is expected to rise. Authors have reviewed various articles on the same and present salient pre and intraoperative checkpoints for early identification of ICA rupture due to sphenoid bone dehiscence and in turn avoidance of this disastrous complication.

\section{Preoperative preparedness}

Adequate knowledge and thorough understanding of the relevant anatomy of not just sella but also nasal cavity, sinuses and parasellar structures is a must, especially through an endoscopic perspective. This may be done via a small preoperative clinical examination followed by an endoscopic survey in the outpatient department if deemed necessary. At the level of nasal cavity, any evident Deviated Nasal septum (DNS) or turbinate hypertrophy must be noted and accounted for. This might prove crucial in planning the access to the lesion and thus the ICA in case of inadvertent rupture. Studious assessment of preoperative Computed Tomography (CT) scan of brain and paranasal sinuses cannot be overstressed as the extent of pneumatisation of sphenoid sinus must be noted along with the position of its septum. This is crucial as it not only directs the access but also provides information about the relationship of cavernous ICA and lateral sphenoid wall. At the same time, it provides a fair clue to the distance between the two ICA's. Fuji et al.[5] stated that in $88 \%$ of the patients, the thickness of bony wall overlying the ICA is less than $5 \mathrm{~mm}$ and thus it forms a very thin barrier and must be kept in mind during sphenoid sinus bone removal which must be done with utmost care. Further 4-20\% patients have a dehiscent bony wall wherein the ICA is separated from sphenoid sinus only by dura and mucosa. This makes them theoretically vulnerable to iatrogenic injuries with the possibility of uncontrollable and life threatening hemorrhages. This makes a CT scan absolutely mandatory prior to any endonasal surgery and also worth noting is that axial sections provide more information about ICA than coronal or sagittal sections [6]. Figure 1.

\section{Intraoperative preparedness}

In the sphenoid sinus, it has been demonstrated that the ICA can be located close to the lateral wall in about $70 \%$ of the patients [7-9].and thus careful manipulation is required not only while removing the sphenoid sinus bone but also the sinus 
mucosa overlying ICA. This becomes even more significant when bony dehiscence is noted. Visible pulsations of the ICA provide yet another clue to the possible dehiscence of ICA and should warn the surgeon against extensive and aggressive maneuvers in the vicinity. Intraoperative preparedness is not limited to prevention but also management of this mega event as the paucity of time and urgent nature of this event may cloud the judgment of the best of surgeons. Various management options include but not limited to packing, direct repair whenever possible, muscle patch and an endovascular repair. Gauge is the most commonly used material for packing and although readily available, should be ept at hand always. Also, sites for harvesting a muscle patch hould be prepared, scrubbed and ready in case of an urgent need of a free muscle patch. These patches have been proved to be more effective than oxidized cellulose in experimental models nd may be harvested from quadriceps or sternocleidomastoid muscle. A multidisciplinary approach is needed in such testing times and while teaming with the radiologist provides an excellent information preoperatively, an endovascular team should always be intimated prior to be readily available in case of such a complication. To conclude, ICA rupture during pituitary surgery is a disastrous complication carrying a high mortality of $22-28 \%$ and although rare, isn't totally unheard of. Steep learning curve and a 2D anatomy view provided by endoscopes require precise hand eye coordination and dexterity which is a must and surgeons should be trained on modules before getting a hands on experience. Absolute avoidance of this complication isn't possible due to ever present anatomical variations and thus mental $\mathrm{k}$ preparedness, high index of suspicion and early recognition are $\mathrm{s}$ the mainstays for determining the ease of surgery and avoidance of this potential pitfall. Prevention is the best treatment for every iatrogenic injury and the integration of knowledge with a experience can result in futher reduction in rates of the same. Being forewarned is being forearmed.

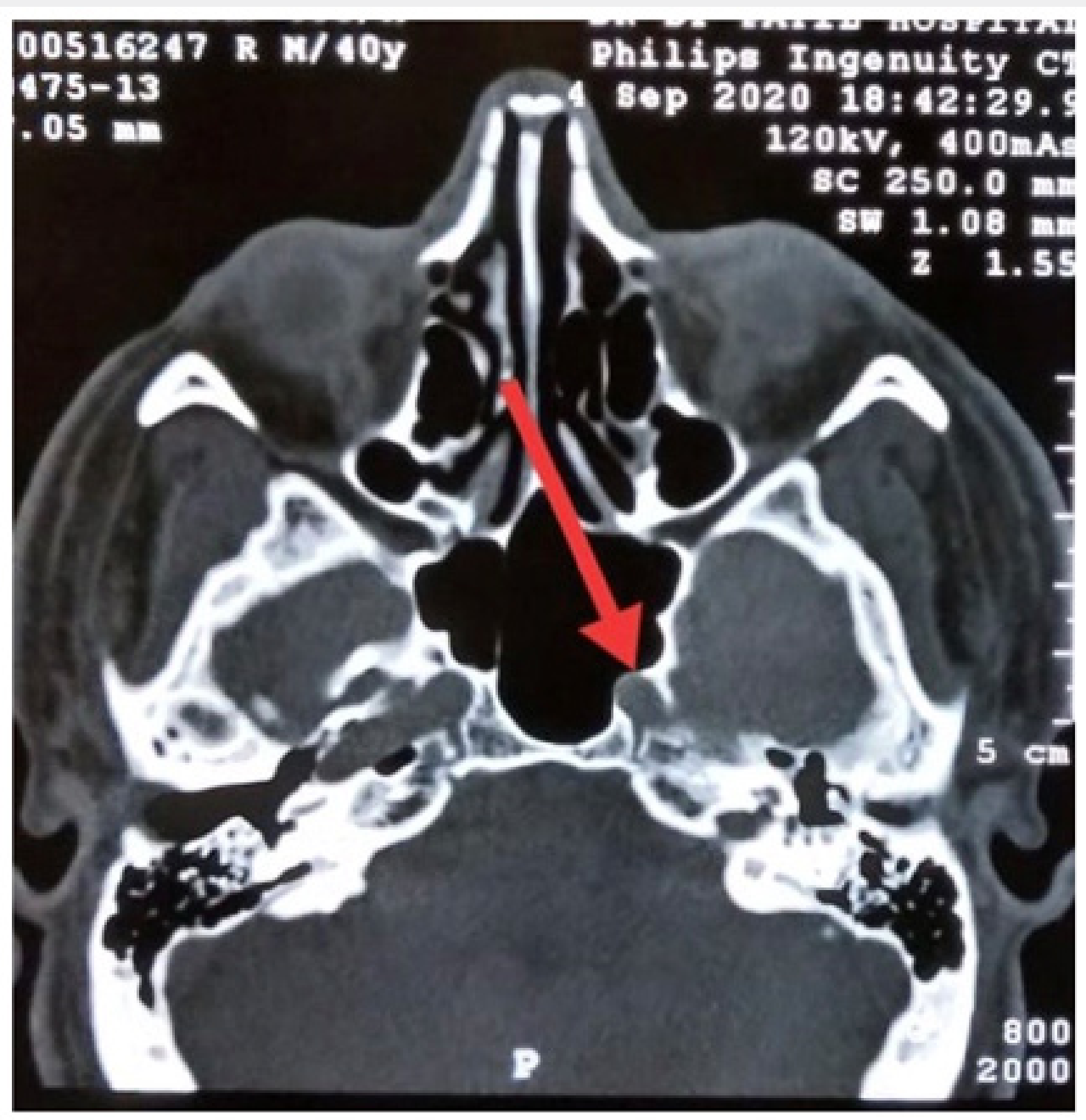

Figure 1 


\section{References}

1. Carrau RL, Kassam AB, Snyderman CH (2001) Pituitary surgery. Otolaryngol Clin North Am 34(6): 1143-1155.

2. Padhye V, Valentine R, Wormald PJ (2014) Management of carotid artery injury in endonasal surgery. Int Arch Otorhinolaryngol 18 (Suppl 2): S173-S178.

3. Singh I, Goyal S, Bisht S, Lssssakshmi ICA injury in sphenoid sinus during nasal endoscopic sinus surgery- A case report. J Otolaryngol ENT Res 5(2): 00133.

4. Solares CA, Ong YK, Carrau RL (2010) Prevention and management of vascular injuries in endoscopic surgery of sinonasal tract and skull base. Otolaryngol Clin North Am 43(4): 817-825.
5. Fujii K, Chambers SM, Rhoton AL Jr(1979) Neurovascular relationships of the sphenoid sinus. A microsurgical study. J Neurosurg 50(1): 31-39.

6. Weidenbecher M, Huk WJ, Iro H (2005) Eur Arch Otorhinolaryngol 262: 640-645

7. Renn WH, Rhoton AL Jr (1975) microsurgical anatomy of surgical region. J Neurosurg 43: 288-298.

8. Valentine R Wormaldt PJ (2011) Carotid artery injury after endonasal surgery. Otolaryngol Clin North Am 44(5): 1059-1079.

9. Valentine R, Boase S, jervis-Bardy J, Dones Cabral JD, Robinson S, et al. (2011) The efficacy of hemostatic techniques in the sheep model of carotid artery injury. Int Forum Allergy Rhinol 1(2): 118-122.

\section{Your next submission with Juniper Publishers will reach you the below assets}

- Quality Editorial service

- Swift Peer Review

- Reprints availability

- E-prints Service

- Manuscript Podcast for convenient understanding

- Global attainment for your research

- Manuscript accessibility in different formats

( Pdf, E-pub, Full Text, Audio)

- Unceasing customer service

Track the below URL for one-step submission

https://juniperpublishers.com/online-submission.php 